TÜSİAD-KOÇ UNIVERSITY ECONOMIC RESEARCH FORUM WORKING PAPER SERIES

THE EFFECT OF COMPULSORY SCHOOLING LAWS ON TEENAGE MARRIAGE AND BIRTHS IN TURKEY

\author{
Murat G. Kurdar \\ Meltem Dayığlu Tayfur \\ İsmet Koç
}

Working Paper 1035

December 2010

TÜSİAD-KOÇ UNIVERSITY ECONOMIC RESEARCH FORUM Rumeli Feneri Yolu 34450 Sariyer/Istanbul 


\title{
The Effect of Compulsory Schooling Laws on Teenage Marriage and Births in Turkey*
}

\author{
Murat G. Kirdar \\ Department of Economics, Middle East Technical University, 06531 Ankara \\ e-mail: kirdar@metu.edu.tr \\ Meltem Dayığlu Tayfur \\ Department of Economics, Middle East Technical University, 06531 Ankara \\ e-mail: dmeltem@metu.edu.tr \\ İsmet Koç \\ Institute of Population Studies, Hacettepe University, 06100, Ankara \\ e-mail: iskoc@hacettepe.edu.tr
}

* We would like to thank İnsan Tunalı, Y. Soner Başkaya, Cem Başlevent and the participants at the Society of Labor Economists, Population Association of America, Economic Research Forum, Society of Economic Dynamics, and Middle East Economic Association conferences and the Econometric Society World Congress as well as the seminar participants at Ryerson University for their helpful comments and suggestions. Financial support from the Turkish Scientific and Technological Council (TÜBITAK) is gratefully acknowledged. All errors are our own. 


\begin{abstract}
This paper estimates the impact of the extension of compulsory schooling in Turkey from 5 to 8 years on the marriage and fertility behavior of teenage women in Turkey using the 2008 Turkish Demographic and Health Survey. We find that the new education policy reduces the probability of marriage and giving birth for teenage women substantially: the probability of marriage by age 16 is reduced by 44 percent and the probability of giving birth by age 17 falls by 36 percent. The effects of the education policy on the time until marriage and firstbirth persist beyond the completion of compulsory schooling. In addition, we find that the delay in the time until first-birth is driven by the delay in the time until marriage. After a woman is married, the rise in compulsory schooling years does not have an effect on the duration until her first-birth. Finally, we find that the education policy was more effective in reducing early marriage than a change in the Civil Code aimed for this purpose.
\end{abstract}

JEL classification: J12, J13, I20, D10

Keywords: Age at marriage, Fertility, Education, Compulsory Schooling 


\section{Introduction}

Adolescent fertility continues to receive wide attention in the literature. The negative association between teenage motherhood and women's education and labor market outcomes as well as their children's health status (e.g. birth weight, higher infant mortality) and teenage mother's higher welfare dependency and involvement in crime have been well documented. Recent studies, however, questioned some of the early associations and embarked on an effort to determine whether a causal relation exists between adolescent fertility and these outcomes. Klepinger et al. (1999), Chevalier and Viitanen (2003), and Fletcher and Wolfe (2009) find that teenage motherhood reduces schooling, work experience and market wages. ${ }^{1}$ Levine and Painter (2003) as well as Holmlund (2005) also confirm that teen-childbearing reduces education substantially. Webbink et al. (2008) find that teenage motherhood increases smoking and the probability of being overweight. On the other hand, studies that investigate the causal relationship between adolescent fertility and child health outcomes have arrived at mixed results (Rosenzweig and Wolpin, 1995; Wolpin, 1997). Intergenerational effects of early childbearing are also reported. Francesconi (2008) finds that children of teenage mothers have lower educational attainment, lower earnings and greater risks of inactivity and teenage childbearing. Hunt (2006) confirms that teenage mothers are more likely to engage in crime. At the macroeconomic level, İyigün (2000) shows that early childbearing may lead to a development trap with low human capital.

Education affects fertility through a number of channels. ${ }^{2}$ Education provides better knowledge of contraceptive methods, which have been shown to be effective in reducing

\footnotetext{
${ }^{1}$ An exception is Hotz et al. (2005), who in fact find positive effects on annual hours of work and earnings.

${ }^{2}$ In his study on low-income countries, Schultz (1994a) estimates that an additional year of schooling for women is associated with a 12 percent decline in total fertility. Glewwe (2002) reviews the literature on the relationship between schooling and marriage and fertility in developing countries.
} 
fertility (Rosenzweig and Schultz, 1985, 1989). Higher opportunity cost of raising children (Becker, 1991), lower infant mortality rates-which lowers the number of births needed to reach the desired family size-(Schultz, 1994b), and higher bargaining power in fertility decisions for more educated women (Mason, 1986) are the other possible channels through which education influences fertility decisions.

In socially conservative countries, where giving birth out-of-wedlock is socially condemned and therefore is rare, mandating teens to stay in school for longer years is a potentially important intervention on childbearing because longer schooling delays the time at which girls enter the marriage market. A delay in the entry to the marriage market implies an automatic delay in childbearing in these countries. In fact, an important characteristic of the transition into motherhood of women in Turkey is that almost all are married at the time of birth. The sociology literature reports a rigid sequence of events of completion of education, marriage, and, birth of the first child in other countries as well (Blossfeld and De Rose, 1992; Marini, 1984). A key fact here is that in this sequence of events, the gap between the age at marriage and first-birth is quite narrow in Turkey. The lapse of time between marriage and first-birth is on average 1.6 years. Given this narrow gap between the timing of marriage and first-birth and the fact that marriage and schooling are generally incompatible events, a change in the timing of marriage as a result of increased schooling would directly translate into a change in the timing of early fertility as well.

In Turkey, the compulsory schooling duration was extended from 5 to 8 years in 1997. In this study, we estimate the causal impact of the new compulsory schooling policy on the timing of marriage and first-birth decisions of teenage women in Turkey. We exploit the variation in the exposure to the policy across different birth-cohorts to find this causal impact. The data set we use for this purpose is the 2008 wave of the Turkish Demographic and Health 
Survey, which is representative nationally and contains detailed information on transitions to marriage and fertility.

Our results indicate that the extension of compulsory schooling in Turkey indeed reduced the probability of marriage and giving birth for teenage women. What is more interesting is that the impact of the extension of compulsory schooling persists beyond the completion of compulsory schooling. We find that the percentage of married women at age 16 drops by 45 percent, and the percentage of women who give birth by age 17, roughly three years after the end of compulsory schooling, goes down by 36 percent as a result of the policy.

That the effect of the policy persists well beyond the end of compulsory schooling suggests that there is a human capital effect of increased compulsory schooling in addition to its incarceration effect. However, another important finding of our study is that the fall in early fertility as a result of increased schooling is driven by the delay in the age at marriage; once a woman is married, we find no evidence of a delaying effect of the policy on the time to first-birth. Therefore, any human capital effect of increased compulsory schooling is certainly limited to the marriage market; the human capital effect plays no role in the time to first-birth after marriage.

Finally, this study also examines the impact of the change in the Civil Code in 2002, which raised the minimum age for marriage, along with the impact of the education policy on teenage marriage. The change in the Civil Code is not found to affect the timing of marriage. In other words, the education policy worked better in reducing teenage marriage and fertility than a change in the Civil Code aimed for this purpose.

The outline of the paper is as follows. Section 2 briefly provides background information on marriage and fertility behavior as well as the education system in Turkey. Section 3 discusses the methodology and the identification strategy used in the paper. Section 
4 presents the results. Section 5 includes a discussion of our major findings and section 6 concludes the paper.

\section{Background Information}

\subsection{Relevant Literature}

In the empirical literature, most of the studies do not go beyond establishing a positive association between education and age at marriage as well as first-birth ${ }^{3}$ due mainly to the difficulty of controlling for unobservable factors that affect both schooling and age at marriage and first-birth. ${ }^{4}$ For instance, if individuals who have a strong preference for schooling also have strong preference to marry late, a positive association between schooling and age at marriage will be observed. Failing to control for such unobservable factors would therefore result in an erroneous conclusion that schooling delays the age at marriage. To overcome this endogeneity problem in the schooling variable, an exogenous variation in schooling is needed.

This exogenous variation in schooling generally comes from natural experiments in the literature. However, due to the difficulty in finding natural experiments, such studiesthat can handle the endogeneity of schooling-are relatively few (e.g. Brien and Lillard, 1994; Skirbekk et al., 2004; Breierova and Duflo, 2004; Osili and Long, 2007; Black et al, 2008; Monstand et al, 2008). These papers, except for Brien and Lillard (1994), overcome the endogeneity problem by using natural experiments as we do.

\footnotetext{
${ }^{3}$ For instance, see Tawiah (1984) for Ghana, Sathar et al. (1988) for Pakistan, Blossfeld and Huinink (1991) for West Germany, Santow and Bracher (1994) for Australia, and Raymo (2003) for Japan.

${ }^{4}$ The simultaneous rise in women's schooling and the fall in marriage rates in the West have spurred a theoretical interest on the reasons for the association between the two phenomena. The prominent theories in this areas are the marriage model of Becker $(1973,1991)$ and the search model of Oppenheimer (1988).
} 
Among those studies, only Black et al. (2008) concentrate on teenage fertility. In fact, Black et al. (2008) also estimate the causal impact of changes in compulsory schooling laws on teenage births. However, there are significant contextual differences in the teenage fertility setting of Black et al.- Norway and the U.S.—and ours. First of all, in Turkey marriage is virtually a necessary condition for teenage fertility (which is explained in more detail in the next section); therefore, unlike Black et al., we study the transition to marriage along with the transition to motherhood. Due to the same reason, the channels through which compulsory schooling affects teenage births are very different from those in the U.S. or Norway. In fact, we examine whether any change in the time to first-birth is caused by a change in the time to marriage or in the time until first-birth after marriage. In addition, the fact that a significant fraction of girls get married as a teenager-more than 22 percent of the 19-year-old women in 2008 were married-and most give birth soon afterwards in Turkey make it an excellent setting to study the impact of schooling on teenage marriage and fertility.

Another important distinguishing characteristic of our study from Black et al. (2004) — as well as from the natural experiments studies in this literature in general—is the strength of the exogenous variation in schooling due to the long duration of the extension of compulsory schooling in Turkey—three extra years—and the high percentage of students whose behavior was actually affected. Monstad et al. (2008) report that the birth-cohorts who were affected by the extension of compulsory schooling in Norway by two years in 1959which is also the policy used by Black et al. (2008) — and who were roughly 5 years younger than the control group had 0.5 years of more education. On the other hand, in our study, the difference in years of schooling is more than a year between the 1986-1990 birth cohortswho are affected by the policy—and the 1981-1985 birth cohorts—who are not affected by the policy (despite the fact that the schooling level of the former group is more likely to be incomplete in 2008). 
Finally, the estimated magnitudes of the policy change in our study are much larger than those in Black et al. (2008). For instance, one of the largest effect they find is that the policy of mandating women to stay in school until age 17 reduces the probability of birth by

age 19 by 8.8 percent in the U.S.. ${ }^{5}$ On the other hand, we find that the policy change in Turkey reduced the probability of giving birth by age 17 by 36 percent.

\subsection{Background Information on Marriage, Fertility, and Education in Turkey}

Despite the rise in non-marital unions in the West, marriage as a social institution remains strong in Turkey. Almost 98 percent of women marry by age 49. In contrast, divorce is an unlikely event, with its rate estimated at less than 1 percent among 15-49 year-old women. Hence, it would not be incorrect to say that for an average woman in Turkey marriage is for life. Giving birth out-of-wedlock is even rarer than choosing an alternative living arrangement. According to DHS data, almost all births are to a married woman. Age at first-birth is also closely linked to age at marriage; the lapse of time between marriage and first-birth is on average 1.6 years.

Marriage occurs early on in life. The average age at first marriage is 20.8 years among women aged 15-49. However, age at marriage and age at first-birth have been increasing and total fertility rate has been declining in Turkey (Figure 1). The DHS data indicate that age at marriage increased from 19.1 years in 1983 to 20.8 years in 2008 and the age at first-birth from 20.6 to 22.3 years over the same time period. Total fertility rate, on the other hand, declined from 4.10 children per woman to 2.15 children per woman over the 20 -year period. Teenage marriage has become less common with the increasing age at marriage; however, it still remains at a quite significant level: 22.2 percent of 19-year-old women were married in 2008, down from 30.3 percent in 1993.

\footnotetext{
${ }^{5}$ They find smaller effects for Norway.
} 
Prior to 2002, the Civil Code stipulated age 15 as the minimum age for marriage for women in Turkey. ${ }^{6}$ In line with the more egalitarian spirit of the new Civil Code, the age at marriage was equated for men and women at age 17 in 2002. ${ }^{7,8}$ However, women could still get married with religious ceremonies before reaching the minimum legal age. For instance, 1.24 percent of all 14-year-old women were married in 1993, when the minimum legal age was 15 . After the minimum age was raised to $17,3.35$ percent of 16-year-old women in 2003, 3.84 percent of 16-year-old women in 2008 were married.

Most people have both religious and civil marriages. However, the fraction of women who have religious marriages only is important. For instance, almost 8 percent of all 15- to 49-year-old women had religious marriage only in 1993 and 1998. This share dropped to 6 percent in 2003 and to 4 percent in 2008. Notwithstanding these changes, the fraction who have religious marriages only remains remarkably high among young women. The fraction of 15- to 19-year-old married women who had only religious marriage was 33 percent in 1993. This fraction dropped only to 29 percent in 2008.

Before the change in the basic education law, the education system in Turkey consisted of five years of primary, three years of lower secondary and three years of upper secondary schooling. Prior to 1997, only the first tier was compulsory. In 1997, the first two tiers were combined so that compulsory schooling increased from five to eight years. Improving the low attendance rates at lower secondary school level was a long established goal. However, the exact timing of the implementation of the new education policy had to do with the political developments of that time. The secular government that came to power in 1997 wanted to prevent young children from enrolling in religious schools. Extension of compulsory schooling could at least delay this for three years.

\footnotetext{
${ }^{6}$ Under unusual circumstances such as pregnancy and with parental consent and court decree, a female child as young as 14 years could get married.

${ }^{7}$ Under unusual circumstances, a 16-year-old is allowed to get married.

8 The Law went into effect on January $1^{\text {st }}, 2002$.
} 


\subsection{Effect of the New Compulsory Schooling Law on Educational Attainment}

In order to examine the relevance of the new compulsory schooling policy with schooling outcomes, we compare the school enrollment rates of 8- to 14-year-old girls before and after the change in policy using the four waves of DHS from 1993 to 2008. This is illustrated in Table 1. Here, we employ a simple difference-in-differences strategy in order to separate the impact of the education policy from a secular improvement in enrollment rates over time. 12- to 14-year-old girls are the ones who are the most likely to be attending grades 6 to 8 ; therefore, they are the ones whose behavior is most likely to change by the policy. The enrollment rate of 12-year-old girls increased roughly by 5 percentage points between 1993 and 1998, and by roughly 10 percentage points between 2003 and 2008; however, it increased by 27 percentage points between 1998 and 2003 - the time interval during which the policy became effective. Similarly, the enrollment rates of 13 and 14-year-old girls both increased by roughly 30 percentage points between 1998 and 2003, whereas the changes in the enrollment rates of girls at these ages were much more modest between 1993 and 1998 as well as between 2003 and 2008. It is also important, at this point, to note the dramatic magnitude of the improvement in enrollment rates with the change in education policy.

It could still be that there was something else, apart from the education policy, that occurred between 1998 and 2003 that increased the enrollment rates of all girls. However, if we compare the change in enrollment rates of girls aged 12-14 with the enrollment rates of younger girls, we see that the substantial increase in the enrollment rates between 1998 and 2003 was limited to girls attending grades 6 to 8 . Even though there is an improvement in the enrollment rates of 8- to 10 year-old girls in 2003 who would not be affected by the policy, this improvement is not any different from the improvement from 2003 to 2008. In fact, the improvement from 2003 to 2008 is higher on average for 8- to 10-year-old girls. Therefore, 
we can assert that the change in compulsory schooling duration brought about a substantial increase in the school enrollment rates at ages targeted by the policy.

\section{Identification Strategy}

We use the variation in the years of compulsory schooling across different birth cohorts to identify the causal impact of the new compulsory schooling policy on the timing of marriage and first-birth decisions. Since the extension of compulsory school was implemented at the beginning of the 1997-1998 school year, all students who completed grade four or lower grades at the end of the 1996-1997 school year (i.e., who started grade four or lower grades in September 1996) were bound by the new policy. In other words, compulsory schooling was for eight years for all students who started the first grade in September 1993 or later; but it was five years for those who started earlier.

Even though not all children start school at the same age, we do not have the information on school starting age of children in our data set. Therefore, we need to assume that all children start school at a certain age. To examine the school start-age, we calculated the percentage of children currently in school by age using the 1993, 1998, and 2003 waves of the DHS. In 1993 and 1998, the mode of school starting age is seven, whereas in 2003 most children start school at age 6. Since our sample includes women of 1978-1998 birth cohorts, most of the women in our sample started school before 1998. Therefore, we chose to take the school starting age as seven. Since the new compulsory schooling system affected children who started school at or after September 1993, we assume that children who were born in 1986 or later were bound by the new policy.

In order to identify the impact of the new compulsory schooling policy, we generate a policy dummy variable. Table 2 shows how the value of this policy variable varies over the birth-cohort and age values that are included in our sample. When the calendar years are in 
bold, the policy dummy variable takes the value of 1 ; otherwise, the policy variable is zero. For all birth cohorts after 1986, the policy variable is one at all ages. For the 1986 birth cohort, it is one after age 11 (calendar year 1997) because the policy was not expected before implementation. For all other birth cohorts, the policy variable is zero at all ages. In addition, a correction is made for children who dropped out of school before 1997 as these children would not be affected by the policy. For instance, the policy dummy variable is zero for children who dropped out at any school level before completing the fourth grade among the 1986 birth-cohort, before completing the third grade among the 1987 birth-cohort and so forth. Therefore, the policy dummy is zero for a small fraction of 1986 to 1989 birth-cohorts. In order to account for the change in the Civil Code, we use a dummy variable for 15- and 16-years-old girls after 2002. In Table 2, the cells for which the new Civil Code is in effect are underlined.

Since different birth cohorts attend a certain grade level at different calendar years, it becomes critical to disentangle the effects of calendar years on education-like a steady improvement in enrollment rates over time-from the effect of the change in the compulsory schooling policy, which is implemented at a certain point in time. Our identification strategy purges the impacts of these two factors. We use the variation in the policy dummy variable across different birth cohorts in identifying the impact of year dummies. For instance, while the policy variable takes the value of one in 2003 for birth cohorts after 1986, it is zero in 2003 for the rest of the birth cohorts as can be seen in Table 2. A similar issue arises in purging the impact of the policy variable from age effects. Here, the source of identification is again the variation across birth-cohorts. For instance, when we examine 15-year-old children in Table 2, we see that the policy dummy is one for birth cohorts after 1986 and zero otherwise. This separates the effect of the policy variable from the age effects. Of course, this identification strategy assumes that there are no age and calendar year interaction effects; i.e. 
the way marriage and fertility behavior change over time is not different across age groups. We also test this assumption using a second specification in which we include time trends that vary across ages. Note that in both specifications our identification strategy assumes that there is no direct impact of year-of-birth variable; i.e. at a given age and calendar year, all year-of-birth cohorts would display the same marriage and fertility behavior.

If the timing of the change in the education policy were correlated with some unobserved characteristics that also affect marriage and fertility decisions, we would get biased estimates. For instance, if the policy change came right after some shock that decreased school enrollment rates while increasing marriage and fertility, there would be a problem. In this sense, it is important to note that the timing of the policy had to do with the political circumstances in 1997. As explained in Section 2, although improving the low lower-secondary school enrollment rates had long been in discussion by policy-makers, the extension of compulsory schooling was implemented in 1997 because the secular government that had recently came to power saw the policy also as a way of preventing young children from attending religious schools. Nonetheless, whether the timing of the policy was correlated with such unobserved characteristics is not testable. ${ }^{9}$

\section{Data and Estimation Method}

The data we employ come from the 2008 round of the Demographic and Health Survey of Hacettepe University of Turkey, which is representative nationally. This survey includes detailed information on the timing of marriage, first and consequent births on evermarried women, as well as a rich set of individual and household-level characteristics for both single and married women. The DHS data include 13,988 women between the ages of 10-49. Of these women, 57.2 percent $(8,003)$ are reported to be either currently or previously

\footnotetext{
${ }^{9}$ Rosenzweig and Wolpin (2000) review the "natural experiments" literature and discuss the assumptions typically made in such studies.
} 
married. However, detailed marriage and fertility information is available for 7,405 of these women, with whom private interviews could be carried out. The number of never-married women in the data is 5,985 .

Using this data, we construct retrospective event histories for marriage and first-birth. The event history starts at age 10 for marriage and at age 12 for first-birth in accordance with the first age that these events are observed in the data. The event history ends when a marriage and fertility takes place or the woman turns 30 -years-old. ${ }^{10}$ A woman could also exit the risk set before age 30 without a marriage/fertility decision if she is younger than 30 in 2008. For some women, the duration is censored in the right because they do not marry/give birth until age 30 or until the last age they are observed in the sample (for those who are younger than 30 in 2008).

When the data are restricted to 10- to 30-year-old women in the marriage analysis, we are left with 8,457 women, of whom 2,752 (32.5 percent) are ever-married. When the data are put into person-age format, there are 72,847 observations. In fertility analysis, where the sample is restricted to 12 - to 30 -year-old women, there are 7,607 women in the sample of whom 2,207 (29 percent) have given birth. In the person-age format, there are 61,477 observations.

In the duration analysis, we use a logistic form for the hazard function given by

$$
\log \left[\frac{h(t, X)}{1-h(t, X)}\right]=\log \Omega(t, X)=b(t)+X \beta
$$

where $t$ denotes the waiting time concept-which is age,$- X$ is the vector of covariates, $h(t, X)$ is the discrete time hazard rate at time $\mathrm{t}$ given $\mathrm{X}, \beta$ denotes the set of parameters to be

\footnotetext{
${ }^{10} \mathrm{We}$ chose age 30 as the upper cut-off point. In choosing this cut-off point, there is a tradeoff between keeping the sample more homogenous and keeping the number of person-age observations relatively high. With age 30 as the upper cut-off point, the proportion of personage observations for which the education policy binds is roughly one-half.
} 
estimated, $\mathrm{b}(\mathrm{t})$ is the baseline hazard rate at time $\mathrm{t}$, and $\Omega(t, X)$ denote the odds of event given $\mathrm{X}$ at time t. Then,

$$
\frac{\Omega\left(t, x, x_{k}+1\right)}{\Omega\left(t, x, x_{k}\right)}=\exp \left(\beta_{k}\right)
$$

Therefore, the estimated parameters can be interpreted in terms of odds ratios.

The baseline hazard function we choose is non-parametric: we use a piece-wise constant baseline hazard where the waiting time concept is age; therefore, we have age dummies for ages 10 to 30 . We allow the impact of the education policy variable to vary according to the baseline hazard in order to see any differential impact of the policy at different age values. ${ }^{11}$

The covariates, $X$, include - in addition to the key variables of interest: dummy variables for the education and Civil Code policies-dummy variables for age as well as calendar year, controls for ethnicity and geographic location at the age of $12 .{ }^{12}$ In the empirical specification, we allow the effect of the ethnicity variable to vary by age. We control for the location of residence by interacting the 12 NUTS-1 level region dummies with three types of location dummies (province center, sub-province, village).

\subsection{Descriptive Statistics}

Table 3 lists the number of non-missing observations, mean values, and standard deviations for the variables in the marriage and fertility samples, separately. Education policy takes the value of 1 in 46 percent of the person-age observations in the marriage sample, and 40 percent of them in the fertility sample. The percentage of person-age observations for which the dummy for the civil code policy takes the value of 1 is lower: 7.6 percent in the

\footnotetext{
${ }^{11}$ On the other hand, the impact of the civil code policy is restricted to be the same at ages 15 and 16 because it is not possible to identify a differential impact.

${ }^{12}$ We define ethnicity based on mother's mother tongue. We take three ethnic groups: ethnic Turks, ethnic Kurds, and ethnic Arabs. All other ethnic groups are grouped with ethnic Turks.
} 
marriage sample and 9.1 percent in the fertility sample. The mean age in the marriage sample is 15.1 , which is much closer to the lower end in the range of 10 to 30 because women exit the sample as they age due to marriage or right-censoring. Roughly 17 percent of the observations in both samples are for ethnic Kurds, and slightly over 2 percent are for ethnic Arabs. In terms of type of location of residence, 45 percent of the observations are from province centers, 22.5 percent are from sub-provinces, and the rest from villages. The region with the largest share of observations is İstanbul, which accounts for almost 15 percent of all observations.

Table 4 reports Kaplan-Meier cumulative hazard rates for marriage and first-birth in our sample. The fraction of women who are married at quite young ages is non-negligible. This fraction becomes especially noticeable after age 15. At age 15, 4.1 percent of the women are already married. This increases to 7.9 percent at the age of 16 . More than a quarter are married by age 19 , and more than a half are married by age 23 . Teenage fertility is also high. By age 16, 2.5 percent of the women have already given birth. This percentage increases to 5.6 for 17 -year-olds. More than 10 percent of the women in our sample have given birth by age 18 , almost a quarter by age 20 , and more than a half by age 24 .

\section{Results}

This section presents the estimation results on the impact of the new education policy on the timing of marriage and first-birth. Robustness checks on these estimation results are also given in this section. In the last part of this section, we examine whether the effect of the new education policy on timing of first-birth works through its effect on the timing of marriage or its effect on the time to first-birth after a woman is married. 


\subsection{Impact of the New Education Policy on the Timing of Marriage and \\ First-Birth}

\subsubsection{Impact of the New Education Policy on the Timing of Marriage}

The results presented in Table 5 indicate that there is evidence that the new education policy reduces the probability of marriage before age 16. (The statistical significance is at the five percent level.) Moreover, the magnitude of the effect of the policy is large. The new policy decreases the odds of marriage by 92 percent for 10-11-year-olds, by 63 percent for 12-13-year-olds, by 49 percent for 14 -year-olds, and by 56 percent for 15 -year-olds. Table 5 also shows that there is no evidence for an impact of the change in the civil code on the probability of marriage.

To have a better sense of the magnitude of the change in the levels of marriage caused by the extension of compulsory schooling, we present in Table 6 how the cumulative hazard rates for marriage change at various ages as a result of the policy. Actual cumulative hazard rates are those that are computed from the data, also given in Table 4. Policy cumulative hazard rates are calculated by first computing the policy hazard rates at each age using the estimated policy variable coefficients in Table 5 and the actual hazard rates at each age ${ }^{13}$, and then cumulating the estimated policy hazard rates at each age up to each age presented in Table 6. We also perform two tests to see the joint statistical significance of the coefficients in Table 5 up to the selected ages in Table 6. First, we calculate the ratio of the policy cumulative hazard rate to the actual cumulative hazard rate at the selected ages to see the percentage drop as a result of the policy, and estimate the 95 percent confidence interval

${ }^{13}$ Policy hazard rates at each age are calculated using the following equation, where $h^{p}($. denotes the policy hazard rate, $h^{a}\left(\right.$.) denotes the actual hazard rate, and $\beta_{t}{ }^{p}$ the effect of the education policy at time $t$.

$$
\frac{h^{p}(t, x)}{1-h^{p}(t, x)}=\frac{h^{a}(t, x)}{1-h^{a}(t, x)} \exp \left(\beta_{t}^{p}\right)
$$


around this ratio to see whether or not this confidence interval lies below 1. Second, we test the equality of the actual cumulative hazard rate to the policy cumulative hazard rate.

According to Table 6, there exists evidence, statistically significant at the five percent level, that the education policy reduces the probability of marriage by age 16 . Moreover, the magnitude of the impact of the policy on the probability of marriage is quite substantial. The policy reduces the probability of marriage by age 15 from 4.12 percent to 1.85 percent, and the probability of marriage by age 16 from 7.85 percent to 4.36 percent. The probability of marriage by age 17 also shows a sizeable decline from 13.2 percent to 11.3 percent; however, this effect is not found to be significant at conventional levels.

The results presented in Table 6 clearly indicate that schooling and marriage are incompatible events. The completion of compulsory schooling years for a girl who starts school at age 7 would take place at age 14 or 15 , and the hazard rates until age 15 exhibit substantial drop as a result of the policy. However, if girls were delaying their marriage decision only because of the fact that schooling and marriage are incompatible events, we would expect the girls who would have married during the new compulsory years were the policy not implemented to marry as soon as they complete the new compulsory schooling years. As a result, an upsurge in the marriage hazard rates right after the end of compulsory schooling would take place. However, according to Table 6, at age 16-more than a year after most girls complete the new compulsory schooling years-the impact of longer schooling years on marriage is still observed. Therefore, we can assert that the effect of the extension of compulsory schooling extends beyond the delay it creates in exposure time.

Our results also indicate that, in contrast to the change in education policy, the change in the civil code that barred marriage for 15- and 16-year-olds had no impact on the probability of marriage at these ages. This result is likely to stem from the fact that in the present study we consider both civil and religious marriages, whereas the civil code only 
affects the former. As noted in Section 2, a considerable fraction of marriages at early ages are through religious ceremonies.

\subsubsection{Impact of the New Education Policy on the Timing of First-Birth}

Table 7 displays the estimates on the impact of the change in education policy on the first-birth decisions. The odds of giving first-birth at ages 14 and 15 are substantially reduced as a result of the policy. (The statistical significance is at the five percent level at age 15 and at the 10 percent level at age 14.) Quantitatively, the odds of giving birth are 71 percent lower at age 14 and 72 percent lower at age 15 as a result of the education policy. These are quite dramatic changes. The odds are also reduced for 12-13-year-olds; however, this effect is not statistically significant at conventional levels due possibly to the small occurrence of the event at such young ages. When we examine the effects at ages that are beyond compulsory school years, we observe reduced hazard rates for first-birth at ages 16 and 17 as well, though the estimated coefficients are not statistically significant at conventional levels.

To see the joint statistical significance of the policy variables age by age and assess the duration for which the effects of the policy are observed, we calculate cumulative hazard rates. These are reported in Table 8 , which shows how the actual cumulative hazard rates at selected ages change as a result of the policy using the estimated coefficients in Table 7. To test the statistical difference between the actual and policy cumulative hazard rates, the 95 percent confidence interval around the ratio of policy to actual cumulative hazard rates as well as a test of the equality of actual and policy cumulative hazard rates are given.

Table 8 shows that the effect of new education policy in reducing the probability of first birth is observed until age 17. The statistical significance level of the evidence that the probability of first birth is reduced as a result of the education policy is at the 1 percent level by age 16 and at the 5 percent level by age 17 . Moreover, the magnitude of the effect of the education policy is quite large: the predicted proportion of women giving birth to their first 
child by age 16 drops from 2.5 percent to 1.3 percent ( 48 percent fall) and by age 17 from 5.6 percent to 3.6 (36 percent fall) percent with the implementation of the new policy.

These findings are consistent with what we found earlier for the timing of marriage. As noted earlier, giving birth out-of-wedlock is an extremely rare event in Turkey. That the age at marriage has registered an increase due to the policy implies an increase for the age at first-birth as well and this is what we find. In this sense, the finding that the statistical significance of the impact of the education policy on marriage persists until age 16 is also in line with the finding that the impact of the policy on first-birth persists until age 17.

\subsubsection{Other Covariates}

At this point it is important to emphasize that the effects of education policy on the timing of marriage and fertility reported in Tables 5 and 7 are obtained after controlling for year and age effects. As shown earlier in Figure 1, a gradual increase in the age at marriage and first-birth has been occurring in Turkey, part of which probably results from a secular increase in the age of marriage and first-birth. In that case, ignoring the time effects would unduly exaggerate the effect of schooling on the timing of marriage.

Our estimated year effects from the marriage and fertility regressions are displayed in Figure 2. While year effects are relatively constant before 2000 for marriage and before 2002 for fertility, they exhibit a substantial downward effect afterwards. For instance, compared to the baseline years of 1988 to 1994, the odds of marriage are 40 percent lower in 2001, and 78 percent lower in 2008. (The statistical significance is at the 1 percent level in both cases.) The odds of first-birth are 48 percent lower in 2008. (This is statistically significant at the five percent level.) This implies that our estimation strategy can account for the negative effect of the education policy on marriage and fertility decisions along with a negative secular time trend effect. 
Age effects in the marriage and fertility regressions are displayed in Figure 3, where the odds ratio at age 25 is normalized to 1 . As expected, at early ages the odds of both marriage and fertility increase substantially by age. However, this comes to a halt in midtwenties. In both marriage and fertility decisions, there is no statistically significant difference between the effect of age 25 and those of all ages between 23 and 30, except for age 30 in the fertility regression where the odds of fertility is lower.

The childhood place of residence, in terms of region of the country and the size of the location of residence, also turns out to be quite important in the marriage and first-birth decisions of these women. Women who spend their childhood in provincial centers are generally less likely to marry and give birth at any age in comparison to women from subprovinces and villages. Regional differences also exist in the probability of marriage and giving birth. Women who spend their childhood outside of İstanbul tend to have a higher likelihood of marrying and giving birth at a given age.

The risk of marrying at young ages is considerably higher among ethnic Kurdish and Arabic women in comparison to ethnic Turkish women. The odds are especially high among the ethnic Kurdish youth between the ages of 10-16. Ethnicity proves to be an important determinant of the timing of first-birth as well. Ethnic Kurdish women are considerably more likely to give birth to their first child before age 18 in comparison to ethnic Turkish women. The differences between the ethnic groups are especially dramatic at very young ages. Ethnic Arabic women are also more likely to give birth before age 18 in comparison to ethnic Turkish women, though up until age 15, the risks of the two groups are similar.

Notwithstanding these findings, it is important to note that the effect of policy remains robust to the inclusion of other covariates (results now shown). This is not a surprising result given that the covariates included in the model are all orthogonal to the policy change. 


\subsection{Robustness Check}

The key identification assumption of Section 5.1 is that there are no age and calendar year interaction effects. However, if marriage and fertility rates decline differentially across age groups over time, this assumption would be violated. Even though it is not possible to identify the impact of age and calendar year interactions along with the effects of the policy, it is possible to allow for a varying impact of time over age groups by incorporating time trends that vary by age along with age dummies and the education policy.

The effects of the education policy on the cumulative hazard rates for marriage at selected ages are shown in Table 9, which is obtained from a logit estimation that includes the interactions of age dummies with a time trend along with all the other variables in Table 5 except for year dummies. (The results of this estimation are reported in Table A1 in the Appendix.) Our results from Section 5.1.1, regarding the impact of the extension of compulsory schooling on the timing of marriage, remain robust. There is evidence, statistically significant at the 1 percent level, that the increased compulsory schooling years decrease the probability of marriage by age 16 . Moreover, the magnitude of this effect is also quite robust. The probability of marriage by age 15 falls by 54 percent-it was 55 percent in Section 5.1.1-and the probability of marriage by age 16 falls by 45 percent, which was 44 percent in Section 5.1.1.

The results of our robustness check for time to first-birth are presented in Table 10, which presents the effects of the education policy on the cumulative hazard rates for firstbirth at selected ages. (The parameter estimates on which Table 10 is based on are given in Table A2 in the Appendix.) Our results regarding the impact of education policy on fertility behavior are also robust. There is strong evidence that the education policy decreases the probability of giving birth by age 17 . In this case, however, there is also some evidence, statistically significant at the 10 percent level, that the probability of giving birth by age 18 is 
reduced by the extension of compulsory schooling. The magnitudes of the effect of the policy are also very similar to our findings in Section 5.1.2. The probability of giving first-birth is reduced by 52 percent at age 16, and by 41 percent at age 17 . The corresponding reductions in Section 5.1.2. were 48 percent at age 16, and by 36 percent at age 17 .

\subsection{Impact of the New Eduction Policy on the Timing of First-Birth after \\ Marriage}

The fall in the fraction of women who give birth at young ages, illustrated in Section 5.1.2, could arise from two different mechanisms. First, it could be brought about by a change in the age at marriage and, in fact, we illustrated in Section 5.1.1 that the fraction of women who get married at young ages also went down. However, there is another mechanism through which the fraction of women who give birth at young ages could go down. As a result of the higher education levels, caused by the education policy, married women could be delaying the birth of their first-child. In this subsection, we tackle this question. Once a woman is married, does an increase in schooling reduce the probability of giving birth to the first-child?

In the duration analysis in this section, women enter the risk set once they are married. The estimation results are presented in Table 11. As can be seen from the table, none of the coefficients of the policy variable at any age is statistically significant. In other words, there is no evidence that once married, the new education policy affects the probability of firstbirth at any particular age. However, cumulative effects of the policy over consecutive agessimilar to those presented in Tables 9 and 11-could be statistically significant. There is, though, a key difference here. In Tables 9 and 11, we started cumulating age effects at ages 10 and 12, respectively, as all women entered the risk set at these ages. In this case, however, women enter the risk set at various ages because marriage takes place at different ages for different women. Therefore, we need to cumulate the coefficients of the policy variable 
starting from every possible age in Table 12. For instance, the coefficient of the policy variable is negative at ages 15,16 , and 17 ; i.e., for a woman who is married at age 15 , the odds of giving her first-birth is lower for three consecutive years. However, once we cumulate the effect of these coefficients, using the methodology of Tables 9 and 11, it still remains statistically insignificant at conventional levels. In fact, whatever age a woman gets married, the cumulative effect of the policy variables in the following ages (for any number of consecutive years) is statistically insignificant. Therefore, we conclude that we find no evidence that the increased compulsory schooling years affect the timing of the first-birth once a woman is married. This result also implies that the source of the increased age at firstbirth that we noted earlier must be the delayed age-at-marriage.

\section{Discussion}

Black et al. (2008) and Monstand et al. (2008) discuss two mechanisms through which education affects fertility. The first one is the incarceration effect according to which schooling as an activity reduces the probability of pregnancy. Incarceration effect ends as soon as children are out of school. The second one is the human capital investment effect, which reduces fertility in the long-term as well by changing the lifetime cost/benefit structure like market wages.

In the Turkish case, it is more appropriate to think about the incarceration and human capital effects on marriage rather than fertility because marriage is virtually a prerequisite for fertility in Turkey and the time from marriage to first-birth has stayed constant at a level of 1.6 years for a long time. We find a very strong incarceration effect of schooling on marriage. The probability of marriage drops substantially during the ages girls are mandated to stay in school with the new education policy. At the same time, we also find that the effect of the new compulsory schooling policy on marriage persists until age 16, more than a year after 
most girls complete the new compulsory schooling years. In fact, the magnitude of the fall at age 17 is also relatively large; however, due to our relatively small sample size, we can not draw conclusions for this age. This suggests that human capital effects play a role as well. However, Tunalı and Yüret (2008) report some spillover effects of the new compulsory schooling scheme on secondary education in Turkey: once they are mandated to stay in school until the end of grade 8, some children who would not complete grades 6 to 8 in the absence of the new policy continue to complete grades 9 and further. Therefore, it is harder to make a strong argument on the existence of human capital effect in Turkey as the incarceration effect may play a role even after compulsory schooling years. In addition, our finding that education has no effect on the time to first-birth after marriage also implies that there is no evidence of a human capital effect on the time until first-birth after marriage.

Black et al. (2008) find only weak evidence of incarceration effect but strong evidence of the human capital effect in the U.S. and Norway whereas it is just the opposite in our case. In Western societies, teenage fertility may not be necessarily planned, it may just happen due to idiosyncratic events. On the other hand, in Turkey, it is clearly planned along with marriage. Therefore, schooling puts a very strong break on teenage fertility in Turkey by preventing marriage whereas it causes just a deceleration in the U.S. and Norway by decreasing the chances of pregnancy.

The finding for a weaker human capital effect in Turkey, compared to those in the U.S. and Norway, is likely to be driven from the different labor market conditions women face in Turkey. A higher level of education increases the opportunity cost of childbearing by increasing the market wage rate. This effect of a higher level of education, however, would be much weaker in Turkey compared to those in the U.S. and Norway. First of all, female labor force participation rate in Turkey is quite low, in particular for women with low levels of education. Therefore, higher wages, if any, do not mean much for the vast majority of 
women. Obviously, higher wages could also pull the participation rates up. However, participation rates do not increase much with higher levels of education in Turkey (the only exception is college graduation). For instance, according to the 2006 Household Labor Force Survey, while the participation rate of women with five years of education in urban areas was 13.3 percent, it was only slightly higher at 15.3 percent for women with eight years of education in urban areas. Therefore, young women in Turkey would be much less likely to delay fertility due to increased labor market opportunities with this particular extension of compulsory education.

Our finding that the increased compulsory schooling years did not change the time to first-birth after marriage means that the time to first-birth increased because the time to marriage increased as a result of the education policy. This stems from the fact that marriage and fertility can be seen as a rigid sequence of events in Turkey, in which the latter comes immediately after the former. Although, as mentioned earlier, age at marriage has increased and total fertility declined considerably over time, the lapse of time between age at marriage and first birth has not registered significant increases over time. The results derived from the 1993, 1998, 2003 and 2008 DHS consistently show that the time from marriage to first-birth has remained stable over time at 1.6 years. This has taken place along with a steady level of childlessness, which is quite uncommon in Turkey-only 1 percent of ever married women are childless at the end of their reproductive period.

\section{Conclusion}

In this paper, we estimate the impact of the extension of compulsory schooling from 5 to 8 years in Turkey on the marriage and fertility decisions of teenage women. We find that the rise in compulsory schooling years indeed reduces the probability of marriage and giving birth for these women. Moreover, the magnitude of this effect is quite substantial. The 
proportion of married women at age 16 drops by 44 percent and the proportion of women who have given birth by age 17 falls by 36 percent as a result of the education policy.

We find a very strong incarceration effect of the new compulsory schooling policy on marriage and, therefore, on the time until first-birth in Turkey. The probability of marriage by age is reduced at all ages until age 15, the ages girls are mandated to stay in school. At the same time, we do not observe a catch-up effect after girls complete compulsory schooling: the probability of marriage in the years after girls leave compulsory schooling, at ages 15 and 16, does not increase. Moreover, the proability of being married at age 16-almost two years after the completion of compulsory schooling - is lower as a result of the new policy. This suggests that the impact of the new education policy on marriage works through human capital accumulation as well. However, the evidence for this mechanism is weaker compared to the incarceration effect.

The delaying effect of the new education policy on first-birth could be brought about by two different mechanisms: by delaying the timing of marriage or by increasing the time until first-birth after marriage (or both). We find that the negative impact of the new education policy on the probability of giving first-birth is driven from the negative impact of the new policy on the probability of marriage. There is no evidence that a higher level of education changes the time until first-birth once a woman is married.

While we find a substantial impact of the new compulsory schooling policy on the time until marriage and first-birth for teenage women in Turkey, we find no evidence that the change in the Civil Code which raised the minimum age for marriage reduced the probability of marriage for teenage women in Turkey. The change in the Civil Code was mostly ineffective because girls could still get married through religious marriages. In fact, an important fraction of marriages at early ages are through religious ceremonies only. However, 
the education policy was successful in preventing marriage-either civil or religious-of teenage women. 


\section{References}

Becker G. A Theory of Marriage, Part I. Journal of Political Economy 1973; 81; 813-846.

Becker G. A Treatise on the Family: Enlarged Edition. Harvard University Press: Cambridge, Mass; 1991.

Black S, Devereux P, and Salvanes, K. Staying in the Classroom and Out of the Maternity Ward? The Effect of Compulsory Schooling Laws on Teenage Births. Economic Journal 2008; 118; 1025-1054.

Blossfeld HP, Huinink J. Human Capital Investment or Norms of Role Transition? How Women's Schooling and Career Affect the Process of Family Formation. American Journal of Sociology 1991; 97(1); 143-168.

Blossfeld HP, and De Rose A. Educational Expansion and the Changes in Entry Into Marriage and Motherhood: The Experience of Italian Women. Genus 1992; 48(3-4); 73-89.

Brien M, Lillard L. Education, Marriage, and First Conception in Malaysia. Journal of Human Resources 1994; 29(4); 1167-1204.

Breierova L, Duflo E. The Impact of Education on Fertility and Child Mortality: Do Fathers Really Matter Less than Mothers? NBER Working Paper 10513; 2004.

Chevalier A, Viitanen TK. The Long-Run Labor Market Consequences of Teenage Motherhood in Britain. Journal of Population Economics 2003; 16; 323-343.

Fletcher JM, Wolfe BL. Education and Labor Market Consequences of Teenage Childbearing Evidence Using the Timing of Pregnancy Outcomes and Community Fixed Effects. Journal of Human Resources 2009; 44: 303-325.

Francesconi M. Adult Outcomes for Children of Teenage Mothers. Scandinavian Journal of Economics 2008; 110(1); 93-117. 
Glewwe P. Schools and Skills in Developing Countries: Education Policies and Socioeconomic Outcomes. Journal of Economic Literature 2002; 40(2); 436-482.

Holmlund H. Estimating Long-Term Consequences of Teenage Childbearing: An Examination of the Siblings Approach. Journal of Human Resources 2005; 40(3); 716-743.

Hotz J, McElroy S, and Sanders S. Teenage Childbearing and Its Life Cycle Consequences: Exploiting a Natural Experiment. Journal of Human Resources 2005; 40(3); 683-715.

Hunt J. Do Teen Births Keep American Crime High? Journal of Law and Economics 2005; 49; 533-66.

İyigün M. Timing of Childbearing and Economic Growth. Journal of Development Economics 2000; 61; 255-69.

Klepinger D, Lundberg S, and Rlotnick R. How Does Adolescent Fertility Affect the Human Capital and Wages of Young Women? Journal of Human Resources 1997; 34: 421448.

Lefgren L, McIntyre F. The Relationship between Women's Education and Marriage Outcomes. Journal of Labor Economics 2006; 24(4); 787-830.

Levine DI, Painter G. The Schooling Costs of Teenage Out-of-Wedlock Childbearing: Analysis with a Within-School Propensity-Score-Matching Estimator. The Review of Economics and Statistics 2003; 85(4); 884-900.

Marini M. Women's Educational Attainment and the Timing of Entry into Parenthood. American Sociological Review 1984; 49; 491-511.

Mason KO. The Status of Women: Conceptual and Methodological Debates in Demographic Studies. Sociological Forum 1986; 1; 284-300.

Monstad K, Propper C, and Salvanes K. Education and Fertility: Evidence from a Natural Experiment. Scandinavian Journal of Economics 2008; 110(4); 827-852. 
Oppenheimer VK. A Theory of Marriage Timing. American Journal of Sociology 1988; 94 (3); 563-591.

Osili UO, Long BT. Does Female Schooling Reduce Fertility? Evidence from Nigeria. Journal of Development Economics 2008; 87; 57-75.

Raymo JM. Educational Attainment and the Transition to First Marriage among Japanese Women. Demography 2003; 40(1); 83-103.

Rosenzweig MR, Schultz TP. The Demand and Supply of Births and Its Life-cycle Consequences, American Economic Review 1985; 75(5); 992-1015.

Rosenzweig MR. Schultz TP. Schooling, Information, and Nonmarket Productivity: Contraceptive Use and Its Effectiveness. International Economic Review 1989; 30(2); 457-477.

Rosenzweig MR, Wolpin KI. Sisters, Siblings, and Mothers: The Effect of Teen-Age Childbearing on Birth Outcomes in a Dynamic Family Context. Econometrica 1995; 63(2); 303-326.

Rosenzweig MR, Wolpin KI. Natural 'Natural Experiments' in Economics. Journal of Economic Literature 2000; 38; 827-74.

Santow G, Bracher M. Change and Continuity in the Formation of First Marital Unions in Australia. Population Studies 1994; 48; 475-496.

Sathar Z, Crook N, Callum C, Kazi S. Women's Status and Fertility Change in Pakistan. Population and Development Review 1988; 14(3); 415-432.

Schultz TP. Human Capital, Family Planning, and Their Effects on Population Growth. American Economic Review 1994a; 84(2); 255-260.

Schultz TP. Studying the Impact of Household Economic and Community Variables on Child Mortality. Population and Development Review 1994b; 10; 215-235. 
Skirbekk V, Kohler HP, Prskawetz A. Birth Month, School Graduation, and the Timing of Births and Marriages. Demography 2004; 41(3); 547-568.

Tawiah EO. Determinants of Cumulative Fertility in Ghana. Demography 1984; 21(1); 1-8.

Tunalı İ, Yüret T. How a Change in Compulsory Attendance Law for Primary Education Increased High School Enrollment in Turkey. 2008; mimeo.

TUIK. Population and Development Indicators. http://nkg.tuik.gov.tr/goster.asp?aile=3.

Webbink D, Martin NG, Visscher PM. Does Teenage Childbearing Increase Smoking, Drinking, and Body Size? Journal of Health Economics 2008; 27; 888-903.

Wolpin KI 1997. Determinants and Consequences of the Mortality and Health of Infants and Children. In: Rosenzweig MR, Stark O. (Eds), Handbook of Population and Family Economics, Vol. 1A. Elsevier: The Netherlands; 1997. p. 483-557. 
Table 1: Enrollment Rates by Age over Time

\begin{tabular}{|c|c|c|c|c|c|c|c|}
\hline Year & Age 8 & Age 9 & Age 10 & Age 11 & Age 12 & Age 13 & Age 14 \\
\hline 1993 & 89.8 & 91.6 & 90.0 & 79.7 & 56.7 & 49.0 & 42.6 \\
\hline 1998 & 85.9 & 91.2 & 89.8 & 80.5 & 61.6 & 58.5 & 39.6 \\
\hline 2003 & 92.4 & 96.3 & 94.2 & 94.7 & 88.7 & 85.1 & 70.2 \\
\hline 2008 & 99.9 & 99.9 & 99.5 & 98.3 & 98.4 & 88.4 & 78.4 \\
\hline
\end{tabular}


Table 2: Education Policy Dummy Variable According to Birth-Cohorts and Age

\begin{tabular}{|c|c|c|c|c|c|c|c|c|c|c|c|c|c|c|c|}
\hline \multirow{2}{*}{$\begin{array}{l}\text { Birth } \\
\text { Year }\end{array}$} & \multicolumn{15}{|c|}{ Calendar Year } \\
\hline & 2008 & 2007 & 2006 & 2005 & 2004 & 2003 & 2002 & 2001 & 2000 & 1999 & 1998 & 1997 & 1996 & $\ldots$ & 1988 \\
\hline 1998 & 10 & & & & & & & & & & & & & & \\
\hline 1997 & 11 & 10 & & & & & & & & & & & & & \\
\hline 1996 & 12 & 11 & 10 & & & & & & & & & & & & \\
\hline 1995 & 13 & 12 & 11 & 10 & & & & & & & & & & & \\
\hline 1994 & 14 & 13 & 12 & 11 & 10 & & & & & & & & & & \\
\hline 1993 & 15 & 14 & 13 & 12 & 11 & 10 & & & & & & & & & \\
\hline 1992 & 16 & 15 & 14 & 13 & 12 & 11 & 10 & & & & & & & & \\
\hline 1991 & 17 & $\underline{16}$ & $\underline{15}$ & 14 & 13 & 12 & 11 & 10 & & & & & & & \\
\hline 1990 & 18 & 17 & 16 & 15 & 14 & 13 & 12 & 11 & 10 & & & & & & \\
\hline 1989 & 19 & 18 & 17 & 16 & 15 & 14 & 13 & 12 & 11 & 10 & & & & & \\
\hline 1988 & 20 & 19 & 18 & 17 & $\underline{16}$ & $\underline{15}$ & 14 & 13 & 12 & 11 & 10 & & & & \\
\hline 1987 & 21 & 20 & 19 & 18 & 17 & $\underline{16}$ & $\underline{15}$ & 14 & 13 & 12 & 11 & 10 & & & \\
\hline 1986 & 22 & 21 & 20 & 19 & 18 & 17 & 16 & 15 & 14 & 13 & 12 & 11 & 10 & & \\
\hline 1985 & 23 & 22 & 21 & 20 & 19 & 18 & 17 & 16 & 15 & 14 & 13 & 12 & 11 & $\ldots$ & \\
\hline 1984 & 24 & 23 & 22 & 21 & 20 & 19 & 18 & 17 & 16 & 15 & 14 & 13 & 12 & $\ldots$ & \\
\hline$\ldots \ldots$ & $\ldots \ldots$ & $\ldots \ldots$ & $\ldots \ldots$ & $\ldots \ldots$ & $\ldots \ldots$ & $\ldots \ldots$ & $\ldots \ldots$ & $\ldots \ldots$ & $\ldots \ldots$ & $\ldots \ldots$ & $\ldots \ldots$ & $\ldots \ldots$ & $\ldots \ldots$ & $\ldots$. & \\
\hline 1978 & 30 & 29 & 28 & 27 & 26 & 25 & 24 & 23 & 22 & 21 & 20 & 19 & 18 & $\ldots \ldots$ & 10 \\
\hline
\end{tabular}


Table 3: Descriptive Statistics

\begin{tabular}{|c|c|c|c|c|c|c|}
\hline & \multicolumn{3}{|c|}{ Marriage Sample } & \multicolumn{3}{|c|}{ Fertility Sample } \\
\hline & \# Obs & Mean & $\mathrm{SD}$ & \# Obs & Mean & $\mathrm{SD}$ \\
\hline Education Policy & 72847 & 0.458 & 0.499 & 61477 & 0.400 & 0.493 \\
\hline Civil Code Policy & 72847 & 0.076 & 0.271 & 61477 & 0.091 & 0.295 \\
\hline Age & 72847 & 15.142 & 4.039 & 61477 & 16.835 & 3.824 \\
\hline Year & 72847 & 2000.802 & 5.101 & 61477 & 2001.618 & 4.614 \\
\hline \multicolumn{7}{|l|}{ Ethnicity } \\
\hline Ethnic Kurdish & 72183 & 0.171 & 0.424 & 61190 & 0.166 & 0.420 \\
\hline Ethnic Arabic & 72183 & 0.023 & 0.160 & 61190 & 0.022 & 0.161 \\
\hline \multicolumn{7}{|c|}{ Type of Place of Residence at Age 12} \\
\hline Province Center & 72285 & 0.458 & 0.493 & 60975 & 0.451 & 0.492 \\
\hline Sub-province & 72285 & 0.224 & 0.423 & 60975 & 0.225 & 0.424 \\
\hline Village & 72285 & 0.318 & 0.476 & 60975 & 0.324 & 0.478 \\
\hline \multicolumn{7}{|c|}{ Region of Residence at Age 12} \\
\hline Istanbul & 72247 & 0.148 & 0.243 & 60936 & 0.144 & 0.241 \\
\hline West Marmara & 72247 & 0.034 & 0.193 & 60936 & 0.034 & 0.194 \\
\hline Aegean & 72247 & 0.110 & 0.238 & 60936 & 0.109 & 0.239 \\
\hline East Marmara & 72247 & 0.077 & 0.230 & 60936 & 0.078 & 0.231 \\
\hline West Anatolia & 72247 & 0.089 & 0.258 & 60936 & 0.089 & 0.260 \\
\hline Mediterranean & 72247 & 0.122 & 0.340 & 60936 & 0.121 & 0.339 \\
\hline Central Anatolia & 72247 & 0.058 & 0.249 & 60936 & 0.059 & 0.252 \\
\hline West Black Sea & 72247 & 0.085 & 0.285 & 60936 & 0.088 & 0.287 \\
\hline East Black Sea & 72247 & 0.037 & 0.221 & 60936 & 0.038 & 0.222 \\
\hline Northeast Anatolia & 72247 & 0.036 & 0.278 & 60936 & 0.036 & 0.275 \\
\hline Central East Anatolia & 72247 & 0.075 & 0.318 & 60936 & 0.075 & 0.317 \\
\hline Southeast Anatolia & 72247 & 0.129 & 0.377 & 60936 & 0.127 & 0.375 \\
\hline
\end{tabular}


Table 4: Cumulative Hazard Rates for Marriage and First-Birth

\begin{tabular}{cccc|}
\hline \multicolumn{3}{c}{ Age at Marriage } & Age at First Birth \\
\hline Age & Cumulative Hazard Rate & Age & Cumulative Hazard Rate \\
\hline \hline 10 & 0.0002 & & \\
11 & 0.0009 & 12 & \\
12 & 0.0016 & 13 & 0.0003 \\
13 & 0.0057 & 14 & 0.0008 \\
14 & 0.0171 & 15 & 0.0035 \\
15 & 0.0412 & 16 & 0.0095 \\
16 & 0.0785 & 17 & 0.0249 \\
17 & 0.1324 & 18 & 0.0558 \\
18 & 0.2108 & 19 & 0.1013 \\
19 & 0.2853 & 20 & 0.1614 \\
20 & 0.3585 & 21 & 0.2417 \\
21 & 0.4305 & 22 & 0.3152 \\
22 & 0.4885 & 23 & 0.3831 \\
23 & 0.5521 & 24 & 0.4549 \\
24 & 0.6053 & 25 & 0.5122 \\
25 & 0.6619 & 26 & 0.5667 \\
26 & 0.7007 & 27 & 0.6211 \\
27 & 0.7314 & 28 & 0.6636 \\
28 & 0.7598 & 29 & 0.7025 \\
29 & 0.7780 & 30 & 0.7321 \\
30 & 0.7841 & & 0.7394 \\
\hline Notes: These are Kaplan-Meier hazard rates. & & \\
\hline
\end{tabular}


Table 5 Logit Estimation Results of the Duration Model for time to Marriage

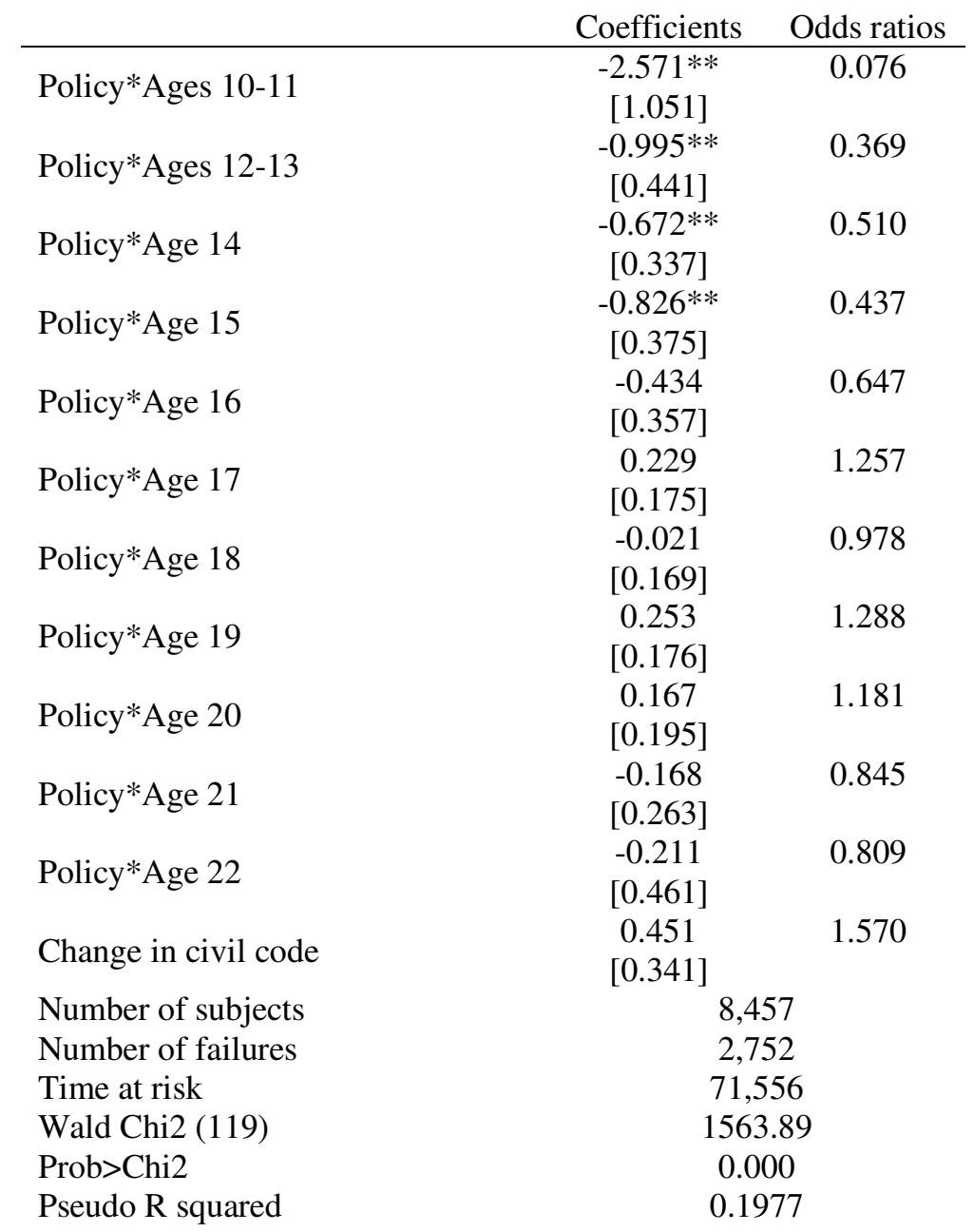

Notes: Robust standard errors are in brackets. * indicates significance at $10 \%, * *$ significance at $5 \%$; and $* * *$ significance at $1 \%$. Other control variables include dummies for interactions between region and size of location of residence until age 12, dummies for interactions between ethnicity and age, as well as calendar year and age dummies. 
Table 6 Effects of the Policy on the Cumulative Hazard Rates for Marriage

\begin{tabular}{ccc|c} 
& Age $=15$ & Age=16 & Age=17 \\
\hline $\begin{array}{ccc}\text { Cumulative Hazard Rate } \\
\text { Actual }\end{array}$ & 0.0412 & 0.0785 & 0.1324 \\
Policy & 0.0185 & 0.0436 & 0.1129 \\
& & & \\
Ratio (Policy/Actual) & 0.4496 & 0.5553 & 0.8528 \\
95\% Confidence Interval & & & \\
$\quad$ Lower Bound & 0.2310 & 0.2521 & 0.6105 \\
Upper Bound & 0.6682 & 0.8584 & 1.0950 \\
Test: Actual=Policy & & & \\
Chi2 & 24.34 & 8.26 & 1.42 \\
Prob>Chi2 & 0.0000 & 0.0040 & 0.2338
\end{tabular}


Table 7 Logit Estimation Results of the Duration Model for time to First-Birth

\begin{tabular}{|c|c|c|}
\hline & Coefficients & Odds Ratios \\
\hline Policy*Ages 12-13 & $\begin{array}{c}-1.702 \\
{[1.099]}\end{array}$ & 0.182 \\
\hline Policy*Age 14 & $\begin{array}{c}-1.244 * \\
{[0.661]}\end{array}$ & 0.288 \\
\hline Policy*Age 15 & $\begin{array}{c}-1.284 * * \\
{[0.631]}\end{array}$ & 0.276 \\
\hline Policy*Age 16 & $\begin{array}{c}-0.420 \\
{[0.317]}\end{array}$ & 0.656 \\
\hline Policy*Age 17 & $\begin{array}{c}-0.312 \\
{[0.218]}\end{array}$ & 0.732 \\
\hline Policy*Age 18 & $\begin{array}{c}0.087 \\
{[0.214]}\end{array}$ & 1.091 \\
\hline Policy*Age 19 & $\begin{array}{c}-0.134 \\
{[0.191]}\end{array}$ & 0.874 \\
\hline Policy*Age 20 & $\begin{array}{c}-0.005 \\
{[0.194]}\end{array}$ & 0.995 \\
\hline Policy*Age 21 & $\begin{array}{c}0.009 \\
{[0.227]}\end{array}$ & 1.010 \\
\hline Policy*Age 22 & $\begin{array}{c}.234 \\
{[0.297]}\end{array}$ & 1.263 \\
\hline Number of subjects & \multicolumn{2}{|c|}{7,607} \\
\hline Number of failures & \multicolumn{2}{|c|}{2,247} \\
\hline Time at risk & \multicolumn{2}{|c|}{60,626} \\
\hline Wald Chi2 (119) & \multicolumn{2}{|c|}{1217.25} \\
\hline Prob $>$ Chi2 & \multicolumn{2}{|c|}{0.000} \\
\hline Pseudo R squared & \multicolumn{2}{|c|}{0.1892} \\
\hline
\end{tabular}

Note: Robust standard errors are in brackets. * indicates significance at $10 \%$, ** significance at $5 \%$; and $* * *$ significance at $1 \%$. Other control variables include dummies for interactions between region and size of location of residence until age 12, dummies for interactions between ethnicity and age, as well as calendar year and age dummies. 
Table 8 Effects of the Policy on the Cumulative Hazard Rate for First Birth

\begin{tabular}{ccc|c} 
& Age=16 & Age=17 & Age=18 \\
\hline Cumulative Hazard Rate & 0.0249 & 0.0558 & 0.1013 \\
Actual & 0.0128 & 0.0359 & 0.0864 \\
Policy & 0.5154 & 0.6439 & 0.8533 \\
Ratio (Policy/Actual) & & & \\
95\% Confidence Interval & 0.2390 & 0.4213 & 0.6064 \\
$\quad$ Lower Bound & 0.7919 & 0.8666 & 1.1003 \\
Upper Bound & & & \\
Test: Actual=Policy & 11.80 & 9.82 & 1.35 \\
$\quad$ Chi2 & 0.0006 & 0.0017 & 0.2445 \\
Prob>Chi2 & & &
\end{tabular}


Table 9 Effects of the Policy on the Cumulative Hazard Rates for Marriage (Time Trends Included)

\begin{tabular}{ccc|c} 
& Age $=15$ & Age $=16$ & Age=17 \\
\hline $\begin{array}{ccc}\text { Cumulative Hazard Rate } \\
\text { Baseline }\end{array}$ & 0.0412 & 0.0785 & 0.1324 \\
Policy & 0.0191 & 0.0430 & 0.1057 \\
& & & \\
Ratio (Policy/Baseline) & 0.4628 & 0.5483 & 0.7985 \\
95\% Confidence Interval & & & 0.5063 \\
$\quad$ Lower Bound & 0.1674 & 0.2436 & 1.0908 \\
Upper Bound & 0.7582 & 0.8530 & \\
Test: Baseline=Policy & & & 1.82 \\
$\quad$ Chi2 & 12.70 & 8.44 & 0.1767 \\
$\quad$ Prob>Chi2 & 0.0004 & 0.0037 &
\end{tabular}


Table 10 Effects of the Policy on the Cumulative Hazard Rate for First-Birth (Time Trends Included)

\begin{tabular}{lcc|c} 
& Age=16 & Age=17 & Age=18 \\
\hline $\begin{array}{l}\text { Cumulative Hazard Rate } \\
\quad \text { Baseline } \\
\text { Policy }\end{array}$ & 0.0249 & 0.0558 & 0.1013 \\
& 0.0120 & 0.0329 & 0.0754 \\
Ratio (Policy/Baseline) & 0.4821 & 0.5903 & 0.7442 \\
95\% Confidence Interval & & & \\
$\quad$ Lower Bound & 0.0878 & 0.2785 & 0.4511 \\
$\quad$ Upper Bound & 0.8764 & 0.9021 & 1.0373 \\
$\quad$ & & \\
Test: Baseline=Policy & & 6.63 & 2.92 \\
Chi2 & 6.63 & 0.0100 & 0.0872 \\
Prob>Chi2 & 0.0100 & &
\end{tabular}


Table 11 Logit Estimation Results of the Duration Model for time to First Birth After

\begin{tabular}{|c|c|c|}
\hline \multicolumn{3}{|c|}{ Marriage } \\
\hline & Coefficients & Odds ratio \\
\hline Policy*Ages 12-13 & $\begin{array}{c}0.111 \\
{[1.248]}\end{array}$ & 1.117 \\
\hline Policy*Age 14 & $\begin{array}{c}0.124 \\
{[0.700]}\end{array}$ & 1.133 \\
\hline Policy*Age 15 & $\begin{array}{c}-0.504 \\
{[0.673]}\end{array}$ & 0.604 \\
\hline Policy*Age 16 & $\begin{array}{c}-0.132 \\
{[0.344]}\end{array}$ & 0.876 \\
\hline Policy*Age 17 & $\begin{array}{c}-0.277 \\
{[0.241]}\end{array}$ & 0.758 \\
\hline Policy*Age 18 & $\begin{array}{c}0.148 \\
{[0.233]}\end{array}$ & 1.159 \\
\hline Policy*Age 19 & $\begin{array}{c}-0.236 \\
{[0.213]}\end{array}$ & 0.789 \\
\hline Policy*Age 20 & $\begin{array}{c}-0.163 \\
{[0.221]}\end{array}$ & 0.849 \\
\hline Policy*Age 21 & $\begin{array}{c}0.096 \\
{[0.266]}\end{array}$ & 1.099 \\
\hline Policy*Age 22 & $\begin{array}{c}.302 \\
{[0.352]}\end{array}$ & 1.352 \\
\hline Number of subjects & & \\
\hline Number of failures & & \\
\hline Time at risk & & \\
\hline Wald Chi2 (119) & & \\
\hline Prob>Chi2 & & \\
\hline Pseudo R squared & & \\
\hline
\end{tabular}

Note: Robust standard errors are in brackets. * indicates significance at $10 \%$, ** significance at $5 \%$; and $* * *$ significance at $1 \%$. Other covariates include ethnicity dummies and their interactions with age, dummies for childhood place of residence and its size as well as their interactions, calendar year and age dummies. 
Figure 1: Total Fertility Rate, Mean Age at First Marriage, and Mean Age at First Birth in Turkey, 1968-2008

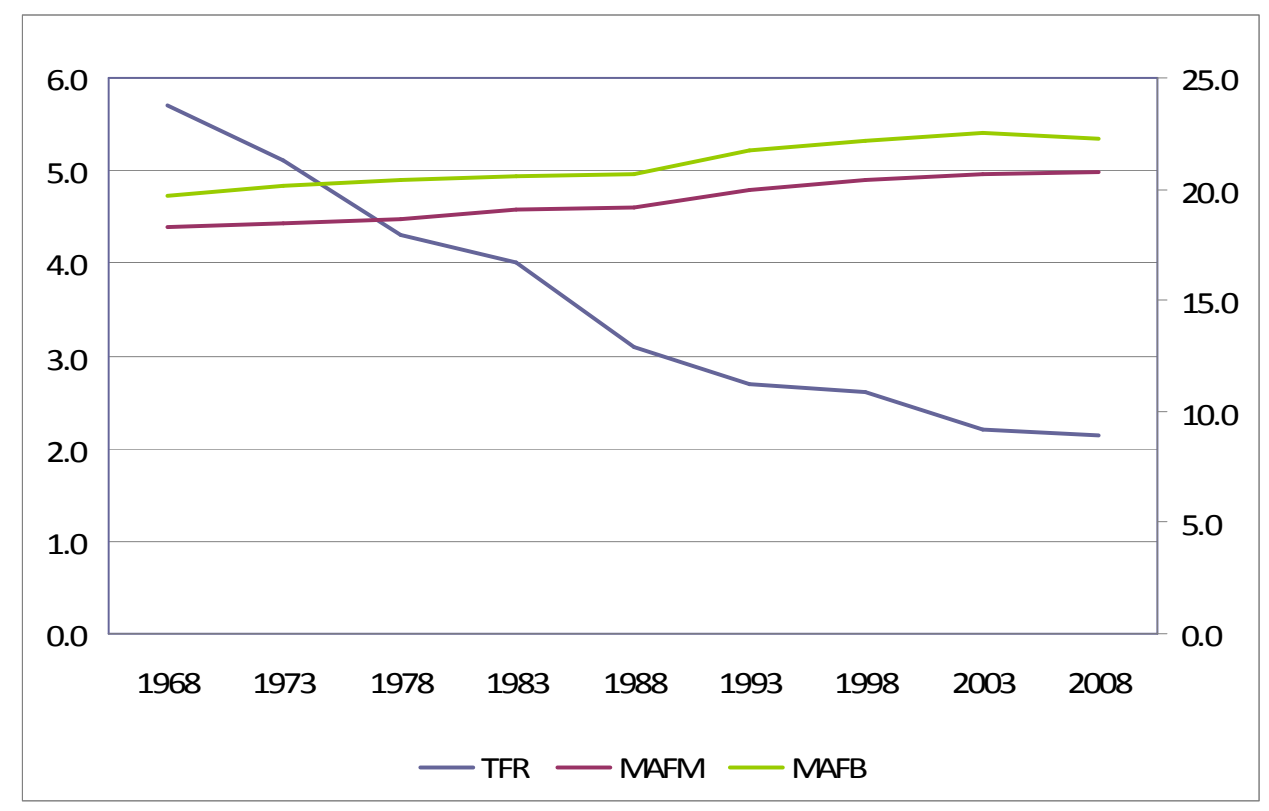


Figure 2: Year Effects in Marriage and Fertility Regressions

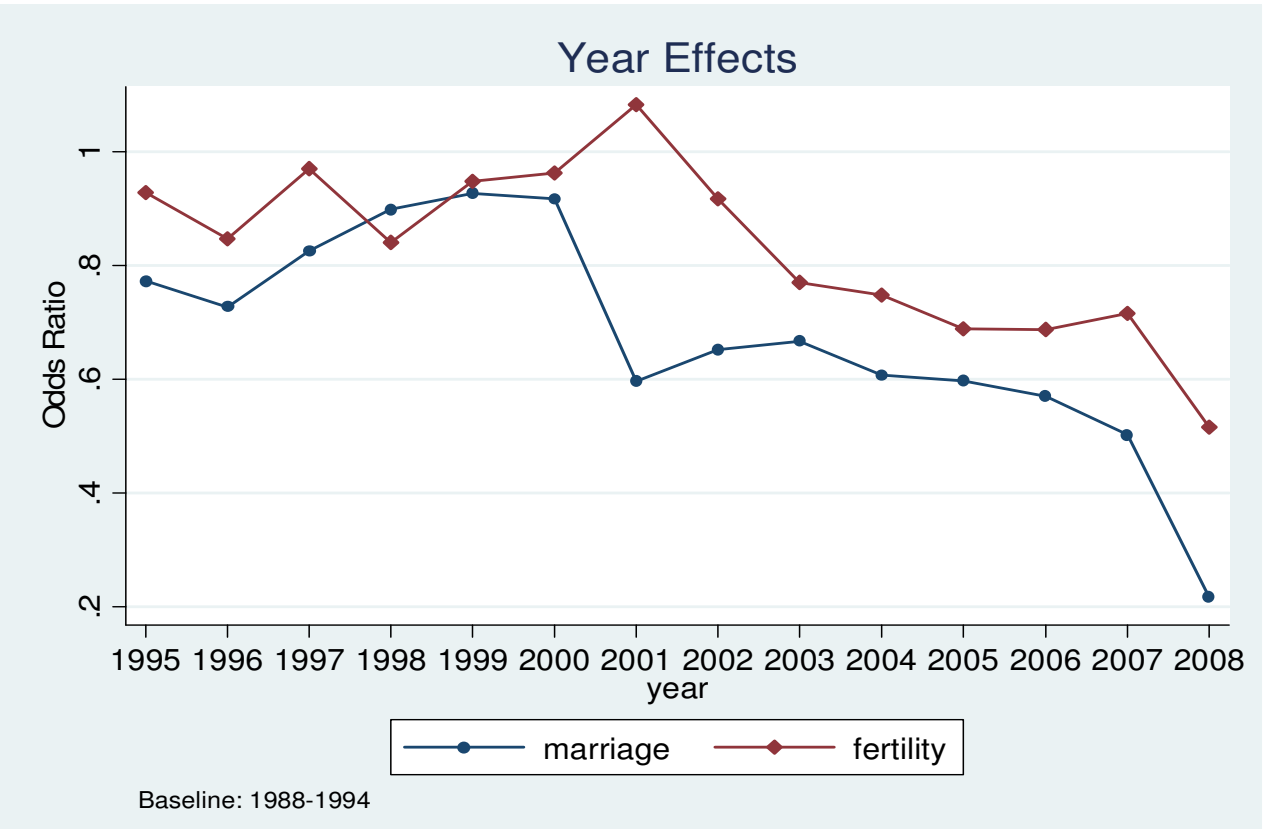


Figure 3: Age Effects on Marriage and First-Birth Regressions

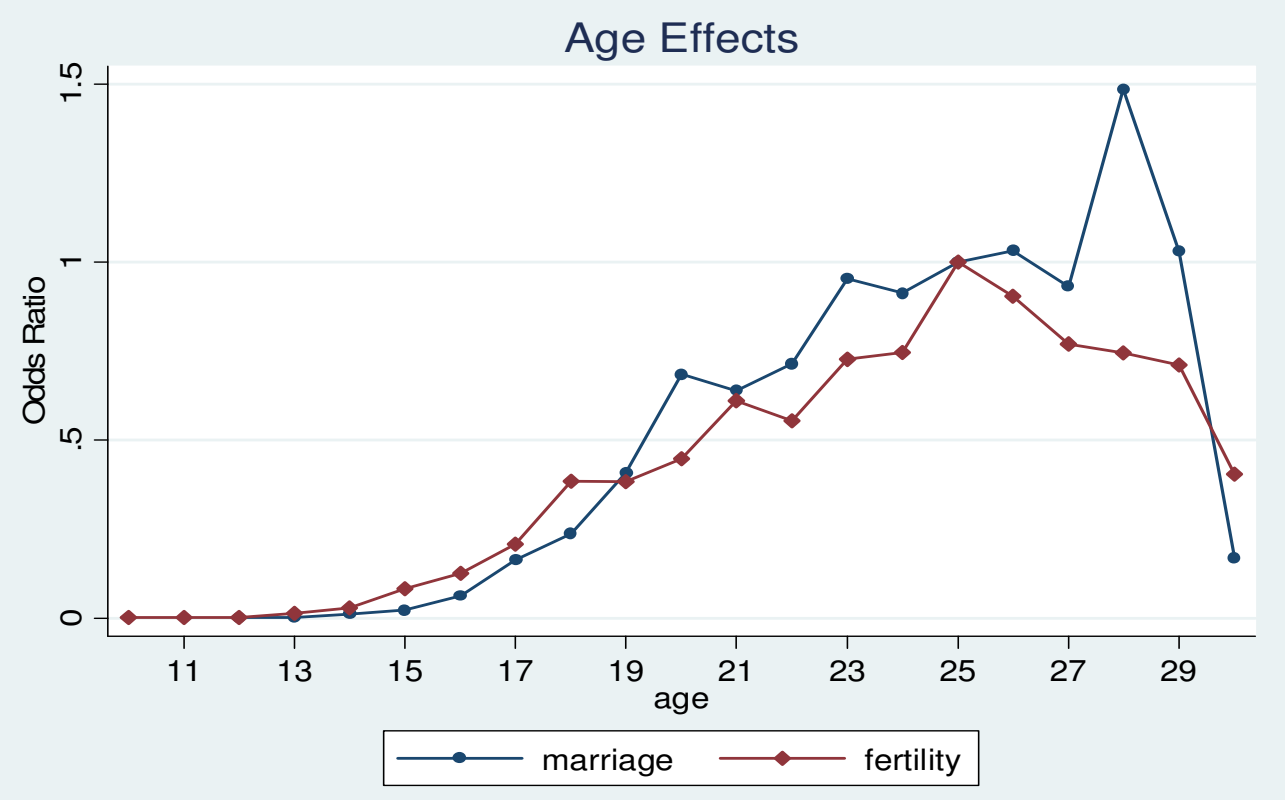




\section{APPENDIX}

Table A1 Logit Estimation Results of the Duration Model for time to Marriage with Time Trends

\begin{tabular}{|c|c|c|}
\hline & Coefficients & Odds ratios \\
\hline Policy*Ages 10-11 & $\begin{array}{c}-0.937 \\
{[1.685]}\end{array}$ & 0.392 \\
\hline Policy*Ages 12-13 & $\begin{array}{l}-0.251 \\
{[0.929]}\end{array}$ & 0.778 \\
\hline Policy*Age 14 & $\begin{array}{l}-0.733 \\
{[0.537]}\end{array}$ & 0.480 \\
\hline Policy*Age 15 & $\begin{array}{c}-0.958 * * \\
{[0.455]}\end{array}$ & 0.384 \\
\hline Policy*Age 16 & $\begin{array}{l}-0.479 \\
{[0.401]}\end{array}$ & 0.619 \\
\hline Policy*Age 17 & $\begin{array}{c}0.121 \\
{[0.278]}\end{array}$ & 1.128 \\
\hline Policy*Age 18 & $\begin{array}{c}-0.222 \\
{[0.255]}\end{array}$ & 0.801 \\
\hline Policy*Age 19 & $\begin{array}{c}0.349 \\
{[0.236]}\end{array}$ & 1.418 \\
\hline Policy*Age 20 & $\begin{array}{c}0.164 \\
{[0.253]}\end{array}$ & 1.178 \\
\hline Policy*Age 21 & $\begin{array}{l}-0.542 * \\
{[0.304]}\end{array}$ & 0.581 \\
\hline Policy*Age 22 & $\begin{array}{c}-1.209 * * \\
{[0.474]}\end{array}$ & 0.298 \\
\hline Change in civil code & $\begin{array}{c}0.451 \\
0.341]\end{array}$ & 1.711 \\
\hline Number of subjects & \multicolumn{2}{|c|}{8,194} \\
\hline Number of failures & \multicolumn{2}{|c|}{2,752} \\
\hline Time at risk & \multicolumn{2}{|c|}{71,556} \\
\hline Wald Chi2 (119) & \multicolumn{2}{|c|}{1518.92} \\
\hline Prob $>$ Chi2 & \multicolumn{2}{|c|}{0.000} \\
\hline Pseudo R squared & \multicolumn{2}{|c|}{0.1947} \\
\hline
\end{tabular}

Note: Robust standard errors are in brackets. * indicates significance at $10 \%, * *$ significance at 5\%; and *** significance at $1 \%$. Other control variables include dummies for interactions between region and size of location of residence until age 12, dummies for interactions between ethnicity and age, as well as age dummies and their interactions with a time trend. 
Table A2 Logit Estimation Results of the Duration Model for time to First Birth with Time Trends

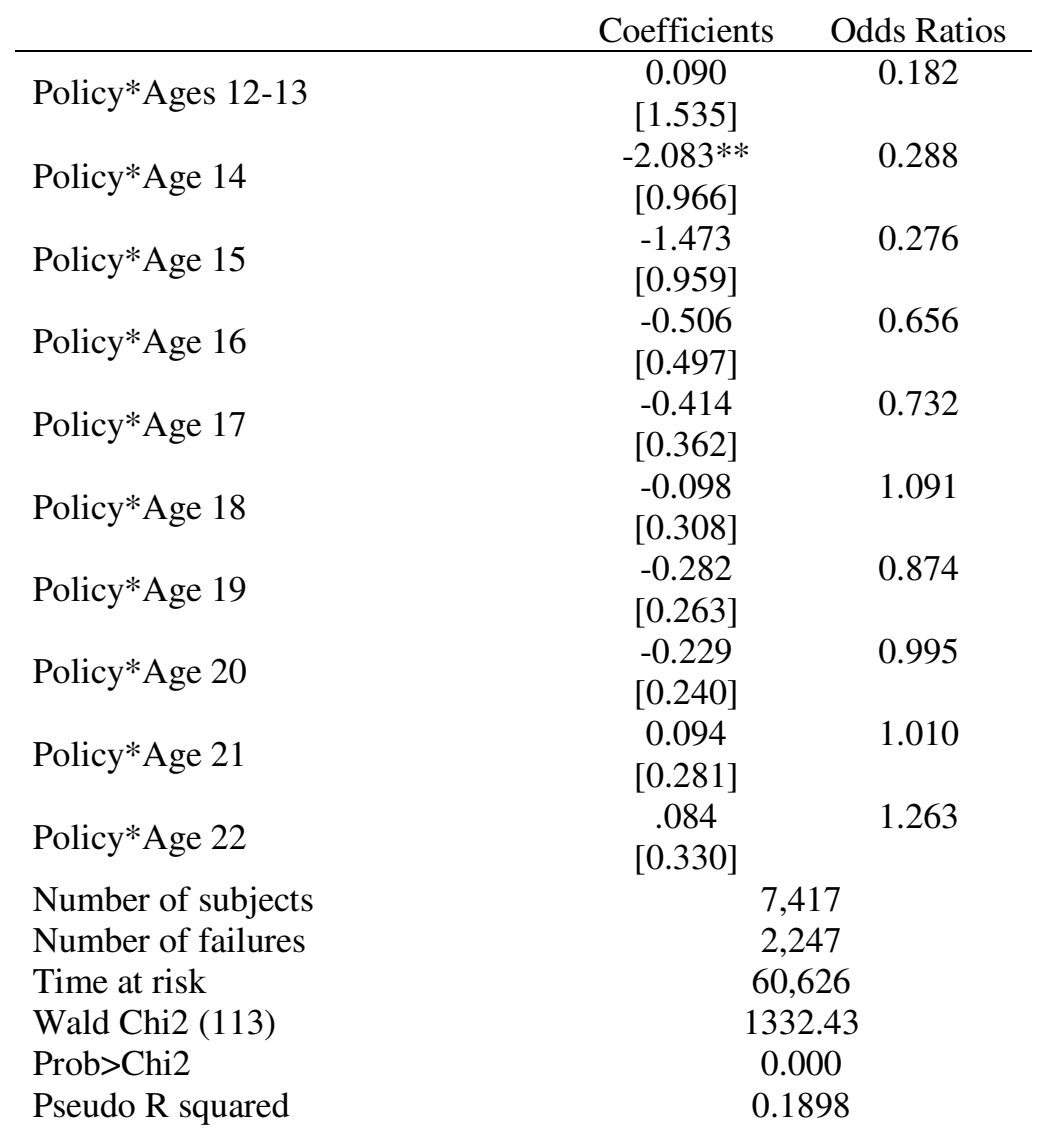

Note: Robust standard errors are in brackets. * indicates significance at $10 \%$, ** significance at 5\%; and *** significance at $1 \%$. Other control variables include dummies for interactions between region and size of location of residence until age 12, dummies for interactions between ethnicity and age, as well as age dummies and their interactions with a time trend. 